Published in final edited form as:

Fertil Steril. 2015 June ; 103(6): 1551-1556.e4. doi:10.1016/j.fertnstert.2015.03.002.

\title{
Optimal timing for elective egg freezing
}

Tolga B. Mesen, M.D. ${ }^{1}$, Jennifer E. Mersereau, M.D., M.S.C.I ${ }^{1}$, Jennifer B. Kane, Ph.D², and Anne Z. Steiner, M.D., M.P.H ${ }^{1}$

Tolga B. Mesen: Tolga_mesen@med.unc.edu; Jennifer E. Mersereau: Jennifer_mersereau@med.unc.edu; Jennifer B. Kane: jbkane@unc.edu; Anne Z. Steiner: Anne_steiner@med.unc.edu

${ }^{1}$ Department of Obstetrics and Gynecology, Division of Reproductive Endocrinology and Infertility, The University of North Carolina at Chapel Hill, Campus Box 7570, Chapel Hill, NC 27599, Telephone: 919-966-1390

${ }^{2}$ Carolina Population Center, The University of North Carolina at Chapel Hill, Room 206, W. Franklin Street

\section{Abstract}

Objective-To estimate the optimal age to pursue elective oocyte cryopreservation.

Design-A decision tree model was constructed to determine the success and cost-effectiveness of oocyte preservation versus no action when considered at ages 25 to 40 years, assuming an attempt at procreation 3,5 , or 7 years after initial decision.

Setting-A hypothetical decision analysis model.

Patients-Hypothetical patients between 25 and 40 years old presenting to discuss elective oocyte cryopreservation.

Intervention(s)-Decision to cryopreserve oocytes between age 25 and 40 versus taking no action.

Main Outcome(s) and Measures-Probability of live birth after initial decision whether or not to cryopreserve oocytes.

Results-Oocyte cryopreservation provided the greatest improvement in probability of live birth compared to no action (51.6\% vs. $21.9 \%$ ) when performed at age 37 . The highest probability of live birth was seen when oocyte cryopreservation was performed at ages younger than 34 (>74\%), although little benefit over no action was seen at ages 25-30 (2.6\%-7.1\% increase). Oocyte cryopreservation was most cost-effective at age 37 at $\$ 28,759$ per each additional live birth in the oocyte cryopreservation group. When the probability of marriage was included, oocyte cryopreservation resulted in little improvement in live birth rates.

(C) 2015 Published by American Society for Reproductive Medicine.

Correspondence to: Tolga B. Mesen, Tolga_mesen@med.unc.edu.

Publisher's Disclaimer: This is a PDF file of an unedited manuscript that has been accepted for publication. As a service to our customers we are providing this early version of the manuscript. The manuscript will undergo copyediting, typesetting, and review of the resulting proof before it is published in its final citable form. Please note that during the production process errors may be discovered which could affect the content, and all legal disclaimers that apply to the journal pertain. 
Conclusion-Oocyte cryopreservation can be of great benefit to specific women and has the highest chance of success when performed at an earlier age. At age 37, oocyte cryopreservation has the largest benefit over no action and is most cost effective.

\section{Keywords}

Elective oocyte cryopreservation; Egg freezing; Fertility preservation

\section{INTRODUCTION}

Over the past several decades the average age of a women's first birth has increased to an all-time high of 25.6 years (1). In 2006, 1 in 12 women had their first birth at age 25 or older, compared to only 1 in 100 in 1970 (2). The cause of the delay in childbearing in western societies is thought to be multifactorial, stemming from both social and economic factors (3). In the United States the age of first marriage has increased since 1950, and in 2009 the mean age of first marriage was 26 years for women (4). The delay in attempted childbearing comes at the cost of an increase in age-related infertility (5).

Standard fertility treatments can only partially overcome the fertility decline associated with aging (6). However, oocyte cryopreservation (OC) can be used as a method of fertility preservation for single women who are not ready to conceive. OC "freezes-in-time" oocyte quality, protecting the higher pregnancy rates associated with the use of younger oocytes (7). Oocyte cryopreservation has been shown to achieve live birth rates consistent with those of fresh oocytes in egg donation cycles (8). While there have been few studies on live birth rates after $\mathrm{OC}$ for fertility preservation, existing literature suggests that the technique is a viable option (9). Recently, committee statements concluded that the use of cryopreserved oocytes is no longer experimental (10) and that "oocyte cryopreservation to improve prospects of future child bearing ... should be available for non-medical reasons" (11). Following these statements, two of the countries largest technology firms, Apple Inc. and Facebook Inc. announced they will provide a $\$ 20,000$ employee benefit to fund OC (www.washingtonpost.com, accessed Oct. 15 ${ }^{\text {th }}, 2014$ ).

Oocyte cryopreservation may offer a viable option for single women wanting to protect against the age-related decline in fertility. However, women and clinicians are now faced with several questions regarding its utilization. What is the live birth rate following $\mathrm{OC}$ for an individual woman? For a given women, to what extent does OC increase the probability of having a baby? At what age should oocytes be cryopreserved? What is the financial cost of banking eggs that may never be used?

The aim of this study was to use decision tree analysis to determine the benefit of OC, in terms of probability of future live birth; dependent on the age of the woman at the time of cryopreservation and intended wait time to pursuing pregnancy. A secondary aim was to determine the cost-effectiveness of OC. 


\section{MATERIALS AND METHODS}

A decision analysis model was constructed (TreeAge Pro 1.0.2, Williamstown, MA) to determine the live birth rate (LBR) and cost-effectiveness when choosing to cryopreserve oocytes for elective fertility preservation compared to taking no action and in the future undergoing unassisted conception attempts for 6 months followed by traditional IVF (see Figure 1 for simplified model). The model mimics the logical progression of a single woman from the time she makes a decision about OC for social indications (Decision Age) to attempting conception 3, 5, or 7 years later (Horizon Ages). The model was run at each Decision Age from ages 25 to 40, allowing for an age-based estimate of the LBR and of the cost-per live birth. This study was considered exempt by the University of North Carolina IRB.

Some women will only attempt pregnancy after marrying, while others will conceive out of wedlock or use anonymous donor sperm. For this reason, we developed two models. In Model A, we assumed that a woman will only attempt to conceive after marriage and included the probability of marriage by the Horizon Age in the decision tree. Model B assumed that all women would attempt pregnancy at the Horizon Age regardless of marital status (with a spouse, partner, or donor sperm).

The tree accounted for the following probabilities: [1] marrying a male by the Horizon Age (Model A only); [2] unassisted conception after 6 months of attempts at Horizon Age; [3] miscarriage (if pregnancy resulted in miscarriage, unassisted conception was attempted for an additional 6 months); [4] LBR using oocytes cryopreserved at Decision Age (IVF-OC); [5] LBR with traditional IVF (IVF-T) at Horizon Age; [6] a $2^{\text {nd }}$ or $3^{\text {rd }}$ IVF-OC cycle and LBRs from these cycles; or [7] a $1^{\text {st }}$ or $2^{\text {nd }}$ frozen embryo cycle (FET) and LBR from these cycles.

Base-case probability data (i.e. probability of a specific event taking place) was compiled from multiple sources including national registries and surveys, ongoing research studies, and medical records from a large national network of infertility practices (IntegraMed) (Table 1). For women ages 25-40, the probability of marriage prior to the Horizon Age was calculated from the National Survey of Family Growth (Supplemental Figure 1a (7-year Horizon shown)) (12). The data for unassisted conception rates after 6 months was derived from 626 women enrolled in an ongoing time-to-pregnancy study, Time to Conceive, as previously described (Supplemental Figure 1b (7-year Horizon shown)) (13). After unassisted conceptions, the age-based LBR versus miscarriage was estimated from a large prospective national register linkage study of over 1.2 million pregnancies in Denmark (Supplemental Figure 1c (7-year Horizon shown)) (14). We assumed that all women who have not achieved live birth by natural methods will be diagnosed as infertile and will proceed with at least one IVF-OC or one IVF-T cycle, depending on the strategy chosen at Decision Age. For women who did not cryopreserve oocytes, LBR after IVF-T were calculated based on her Horizon Age using the 2011 CDC ART National Summary Report, which includes outcome data from 101,213 fresh, non-donor IVF cycles from 451 centers in the United States (Supplemental Figure 1d (7-year Horizon shown)) (15). For women who decided to freeze oocytes, but failed to conceive naturally and were thus infertile, we 
derived LBR for IVF-OC cycles from the same CDC ART data, but used her 'Decision Age' (as opposed to Horizon Age) to estimate LBR (Supplemental Figure 1e (7-year Horizon shown)).

The probability of a $2^{\text {nd }}$ or $3^{\text {rd }}$ IVF-OC cycle was calculated from the IntegraMed system database. The number of metaphase II (MII) oocytes, by female age, from 33,821 IVF cycles performed between 2003-2013 in women with the diagnosis of male or tubal factor infertility was used to estimate the number of oocytes available for cryopreservation at the Decision Age. Patients who underwent oocyte retrieval for male or tubal factor infertility were presumed to have an oocyte yield similar to age matched women undergoing retrieval for elective oocyte cryopreservation. To determine the probability of a $2^{\text {nd }}$ or $3^{\text {rd }}$ IVF-OC cycles (if no live birth had occurred) we assumed that women with $\leq 8$ oocytes were eligible for only 1 cycle, women with 8-16 oocytes would pursue a second IVF-OC, and women with $\geq 17$ oocytes were eligible for a third IVF-OC (Supplemental Figure 1f (7-year Horizon shown)).

For those in the IVF-T branch who did not conceive after the fresh IVF cycle, we used the IntegraMed database to determine the probability of having supernumery embryos for a $1^{\text {st }}$ and $2^{\text {nd }}$ FET. Data about the number of embryos frozen from 35,279 IVF cycles for all ages between 25 and 46 in women with tubal or male factor infertility was compiled. The number of embryos to transfer per FET were based on "unfavorable criteria" from the 2012 ASRM committee opinion; this allowed us to estimate the probability of 0,1 , or 2 FET for all ages between 25 and 40 (Supplemental Figure 1g (7-year Horizon shown)) (16). The LBR for the $1^{\text {st }}$ and $2^{\text {nd }}$ FET were assumed to be equivalent to IVF-T at the age of retrieval (horizon age) based on CDC ART 2011 reporting data (15).

Charges were interpreted from a societal prospective and adjusted to 2014 dollars using a using the Consumer Price Index (www.bls.gov/data/CPI) (17-20). Direct charges including costs of medications, laboratory costs and medical services including procedures were included in the model (Table 1). Indirect costs, such as loss of productivity were not included in the calculations. Additionally, to simplify the model, costs associated with pregnancy outcomes such as cost of miscarriage, preterm delivery, or twin/higher order multiple pregnancy are not included.

Prior to analyzing the models, we determined that an increase in LBR of $10 \%$ was clinically significant. This was consistent with power calculations of large randomized controlled trials studying interventions in IVF (21). An overall probability of live birth of $>70 \%$ was considered excellent.

To assess the robustness of the models and account for error in probability and cost estimates, we utilized a one-way sensitivity analyses on all variables. We performed this analysis only for the Decision Ages with the largest difference in LBR and the lowest incremental cost-effectiveness ratio (ICER). The ICER is the ratio of overall difference in cost between choosing OC versus not choosing OC divided by the incremental increase in live birth $\left(\left(\mathrm{ICER}=\right.\right.$ Cost $_{\mathrm{OC}}-$ Cost $\left._{\mathrm{No}} \mathrm{OC}\right) /($ Probality Live Birth $\mathrm{OC}-$ Probality Live BirthNo OC)), this can also be interpreted as the cost per additional live birth when 
performing OC. When a precise range of cost or probability was not known from the literature, a 50\% range of the base-case value was assumed. All variables in the decision model were analyzed independently.

\section{RESULTS}

In Model A, accounting for the probability of marriage, the greatest difference in probability of live birth with OC was $5.6 \%$ at age $35(14.7 \%$ vs. $9.1 \%)$ with a 7 -year horizon. In this model LBR never surpassed the predetermined threshold of an increase of $10 \%$. The highest probability of live birth was seen when oocyte cryopreservation was performed at ages 2530 (53.5\%-32.3\%), although the increase in LBR over expectant management was very small $(<3 \%)$. Both scenarios approached a $0 \%$ probability of live birth at age 40 , due to the small chance of marriage within 7 years $(16 \%)$ combined with poor IVF LBR $(17.5 \%)$ in the oocyte cryopreservation group and low likelihood of achieving pregnancy with autologous oocytes by any means at age $47(<1 \%)$ (Figure 2, Supplemental Table 1$)$. The benefit of OC in terms of probability of LBR was further diminished with a 3- or 5-year horizon (Supplemental Figure 2).

In Model A, oocyte cryopreservation was most cost-effective, although still substantially higher in cost than electing to not cryopreserve oocytes, at age 35 with a 7-year horizon. At this age and horizon, the average projected cost of electing the OC arm was $\$ 12,910$ per individual, while only $\$ 2,111$ in the no action arm. The societal cost for each additional live birth (ICER) in the oocyte cryopreservation group was $\$ 196,032$. Oocyte cryopreservation was least cost-effective between ages 25-30 with an ICER of \$366,824-\$698,722 (Figure 3, Supplemental Table 1).

For Model B (women will proceed with pregnancy attempts regardless of marital status, using donor sperm if necessary) starkly different results were obtained. In this model, at the 7 -year horizon, the greatest difference in the probability of live birth was $29.7 \%$ at a Decision Age of 37 (51.6\% LBR for OC vs. 21.9\% LBR for 'no action'). The difference in LBR was greater than the predetermined threshold value of $10 \%$ for Decision Ages over 30 . The probability of live birth was excellent (>70\%) if OC was performed prior to age 34 , with a gradual decrease in LBR until a low of $26.2 \%$ if performed after age 40 (Figure 2, Supplemental Table S1). The benefit of OC in terms of improved LBR is decreased with 3and 5-year horizons (Supplemental Figure 1).

In Model B, OC was most cost-effective at age 37 with a 7-year horizon. The average projected cost at this age was $\$ 19,493$ when OC was performed and $\$ 10,943$ when no action was taken. The ICER in this scenario was $\$ 28,759$. Once again, oocyte cryopreservation was least cost-effective when performed at younger ages with maximum ICER of \$406,508 at age 25 (Figure 3, Supplemental Table 1).

A one-way sensitivity analysis was performed using Decision Ages and Horizon at which the greatest increase in probability of pregnancy and lowest cost-per additional live birth in both models was observed (35 yo for Model A and 37 yo for Model B, 7-year Horizon). When adjusting individual variables over ranges of cost or probabilities, there were no 
instances in Model A where OC was a cost-saving modality (Supplemental Table 2). In Model B, the strategy to cryopreserve oocytes was more cost-effective when the cost of IVF exceeded $\$ 23,862$. Adjusting the cost and probability of other variables had no effect on cost dominance (Supplemental Table 2).

\section{DISCUSSION}

We have developed an analytic model to estimate the utility and timing of fertility preservation with oocyte cryopreservation for elective indications. The results of the decision tree analysis suggest the largest improvement in LBR is seen when women are accepting of attempting pregnancy regardless of the sperm source (husband sperm, partner sperm, or donor sperm). The LBR was highest in both models when OC was performed at a younger age. However, the absolute benefit of OC over electing not to cryopreserve oocytes was small $(<10 \%)$ at ages less than 32 years in both models. When marriage rates were considered (Model A), the absolute benefit of OC over electing not to cryopreserve oocytes was never greater than $10 \%$. The largest improvement in LBR of $29.7 \%$ is seen in Model B at age 37 with a 7-year horizon; however at this age, the LBR is relatively low with both strategies (51.6\% LBR with OC versus 21.9\% LBR with no action). Using base-case costs and probabilities, $\mathrm{OC}$ was never a cost saving modality; the lowest cost-per additional live birth was $\$ 28,759$ at age 37 (7-year Horizon) when marriage rates were not considered.

In order to account for differences in social practices relating to family building, separate models were created. In Model A, only women who married, attempted pregnancy. While we recognize that this assumption is not appropriate for all women, some single women, who are considering $\mathrm{OC}$, anticipate using these oocytes only following partnering and are not willing to use donor sperm. For these women, Model A results are most appropriate. In this scenario, due to relatively low chances of finding a spouse, the overall LBR is severely limited; there is only a small increase in LBR with OC over taking no action. Because of this, the cost of gaining one additional live birth by OC is very large across all ages. The decreased LBR and high ICER is the direct result of the low probability of marriage.

Prior studies of the utility of $\mathrm{OC}$ for fertility preservation have not considered marriage rates (22-24). The National Survey of Family Growth (2006-2010) is a survey representative of the US population, encompassing multiple socio-economic levels and geographic regions. The probability of marrying later in life is higher in women with a bachelor's degree compared to those without a college degree (25). Assuming 1) college education is a surrogate for socio-economic status and 2) only women with disposable income can consider oocyte cryopreservation given its high initial cost, Model A may slightly underestimate the LBR with both OC and 'no action'. Data on marriage trends in more urban environments is not available. The marriage data used in this model does not account for the probability that a divorced woman may remarry.

Not all women considering OC for fertility preservation will insist on marriage prior to attempting conception. $6.5 \%$ of individuals in their thirties and $4.4 \%$ of individuals in their forties are in unmarried partner unions (26). In $201140.7 \%$ of births were to unmarried women- a $22 \%$ increase since 1980 (1). About 1 in 5 births to women in their thirties are in 
unmarried women (27); approximately half of these births are among women cohabitating with their partner (28). For such women, Model B, which does not include marriage rates, may be more appropriate.

The benefits of OC are more apparent in Model B, when we assume that all women will attempt pregnancy, either with a spouse, partner, or donor sperm. In this situation, in women age $<32$, LBR was high ( $>70 \%$ ) in both the OC and 'no action' groups and the difference between decisions was low $(<10 \%)$. The first age point when OC had a LBR $>70 \%$ and a LBR difference from 'no action' was $>10 \%$ was 32 years. However, at this age, the cost-per additional live birth was high $(\$ 73,439)$.

Two previous cost-effectiveness analysis have been performed, both looking at static decision and horizon ages. A Markov model created by van Loendersloot et al. compared the cost effectiveness of oocyte cryopreservation in 35 year olds deciding between natural conception, IVF-T, and IVF-OC and attempting pregnancy at age 40 from a European prospective. They found IVF-OC to be more effective than both natural conception and IVF$\mathrm{T}$, but at an addition cost of $€ 13,156$ per each additional live birth (22). Hirshfeld-Cytron et al. in the US compared OC to no action at age 25 followed by attempting pregnancy at age 40 and found "no action" to be the most cost-effective route. However, they did find an increase in LBR in the OC arm (79.2\% vs. 71.8\%) (23). Neither of these studies accounted for marriage or partnering rates.

For the individual patient, a societal cost or cost-per additional live birth has little meaning. The cost of action or no action and the probability of success are the most important factors. In both models and all decision ages and horizon periods, OC has a larger overall cost to the individual than no action, arising from the large initial cost of OC. However, in all scenarios, $\mathrm{OC}$ does increase the LBR in the future. If the only consideration is maximizing LBR at any cost, then OC should be performed prior to age 34 . Undergoing OC in the early thirties has a larger impact on LBR when delays in attempts to conceive are longer (7 years) and less impact when delays in attempts to conceive are shorter ( 3 or 5 years) (Supplemental Figure 2).

For single women in their mid- to late thirties, who would consider using donor sperm or sperm from a non-spousal partner, OC will significantly increase the probability of a future live birth. Although the overall highest probability of live birth after OC is seen at younger ages, the largest benefit (versus no action) is seen at the later ages. In fact, in Model B, when approaching age forty and considering a 7-year horizon, OC can salvage the possibility of procreation with one's own eggs. If the objective of $\mathrm{OC}$ is to maximize the costeffectiveness, then OC should be performed at age 35 (Model A) or age 37 (Model B).

Cil et al. recently conducted a meta-analysis of 1805 individual patients from previous studies on OC (24). In these studies, excess oocytes were cryopreserved because embryo cryopreservation was legally or socially prohibitive to the patient. Similar to the results of our decision tree model, the meta-analysis found that $\mathrm{OC}$ at age 36 had the highest discrimination capacity for live birth. This finding further validates our finding of the largest increase of effectiveness of $\mathrm{OC}$ at age 35 or 37 depending on model choice. 
Although our study provides a useful tool to counsel patients when discussing the utility and timing of OC for fertility preservation it does have limitations. The models in this study assumes a 3-, 5-, or 7-year horizon from the time of initial decision about OC. The Horizon Ages chosen were arbitrary. OC is a relatively new technology; ASRM has just recently considered it to be no longer experimental (10). Data on the average time to use of electively cryopreserved oocytes are not available and will unlikely be compiled in the immediate future. Additionally, this model assumes women at the decision age are naïve to fertility testing; these models are not appropriate for infertile women or women with documented decreased ovarian reserve. Decision analysis models rely on the quality of data used to determine the base-case variables. In this study the LBR of embryos derived from cryopreserved oocytes was assumed to be equivalent to LBR rates of embryos derived from IVF at the women's age at time of OC (8). A previous decision analysis used a lower LBR in women attempting pregnancy using cryopreserved oocytes (23). Our estimate may overestimate the efficacy of OC. Additionally, data on unassisted pregnancy rates for women over age 43 were not available and were projected using a model. Also, the CDC data for women over 40 may overestimate pregnancy rates, as women with poor ovarian reserve may be discouraged from doing IVF. However, we attempted to account for potential variance in all of the base-case probability measures by performing one-way sensitivity analyses.

There are many strengths to this decision model. First it evaluates the utility of OC for a wide range of decision ages. In addition, it uses base-case data from large, nationally representative data sets. Access to these databases allowed the use patient level data. Previous analytic models have relied on results from meta-analyses. Data on natural conception rates were derived from a prospective, time-to-pregnancy cohort study of US women of older reproductive ages. Previous studies have lacked such data. Numerous factors are considered in the model, mimicking "real life" scenarios. Finally, the inclusion of data on marriage trends make the results more generalizable.

The results from these models can be used as a tool for physicians providing fertility preservation counseling to their patients. An online calculator using data from this model has been made available to both patients and physicians at www.UNCfertility.com/eggbanking-calculator. These models allow the woman to determine her individual probability of having a biologic child with or without oocyte cryopreservation, aiding in her decision as to whether and when to cryopreserve oocytes. OC is a potentially useful tool for the properly selected patient, although at a high cost per additional live birth.

\section{Supplementary Material}

Refer to Web version on PubMed Central for supplementary material.

\section{Acknowledgments}

FUNDING SOURCE: Funding provided by NIH/NICHD grant R01067683 and K99 HD075860. 


\section{REFERENCES}

1. Martin, JA.; Hamilton, BE.; Ventura, SJ. National vital statistics reports. Vol. 62. Hyattsville, MD: National Center for Health Statistics; 2012. Births: final data for 2011. (DHHS publication no. 2014-1120).

2. Mathews, TJ.; Hamilton, BE. NCHS data brief, no 21. Hyattsville, MD: National Center for Health Statistics; 2009. Delayed childbearing: More women are having their first child later in life. (DHHS publication no. (PHS) 2009-1209).

3. ESHRE Capri Workshop Group. Social determinants of human reproduction. Hum Reprod. 2001; 16:1518-1526. [PubMed: 11425841]

4. Kreider, RM.; Ellis, R. Current population reports. Washington, DC: U.S. Census Bureau; 2011. Number, timing, and duration of marriages and divorces 2009; p. 70-125.

5. van Noord-Zaadstra BM, Looman CW, Alsbach H, Habbema JD, Velde te ER, Karbaat J. Delaying childbearing: effect of age on fecundity and outcome of pregnancy. BMJ. 1991; 302:1361-1365. [PubMed: 2059713]

6. Luke B, Brown MB, Wantman E, Lederman A, Gibbons W, Schattman GL, et al. Cumulative birth rates with linked assisted reproductive technology cycles. N Engl J Med. 2012; 366:2483-2491. [PubMed: 22738098]

7. Lockwood GM. Social egg freezing: the prospect of reproductive "immortality" or a dangerous delusion? Reproductive BioMedicine Online. 2011; 23:334-340. [PubMed: 21775211]

8. Cobo A, Meseguer M, Remohí J, Pellicer A. Use of cryo-banked oocytes in an ovum donation programme: a prospective, randomized, controlled, clinical trial. Hum Reprod. 2010; 25:2239_ 2246. [PubMed: 20591872]

9. Cobo A, Garcia-Velasco JA, Domingo J, Remohí J, Pellicer A. Is vitrification of oocytes useful for fertility preservation for age-related fertility decline and in cancer patients? Fertil Steril. 2013; 99:1485-1495. [PubMed: 23541405]

10. The Practice Committees of the American Society for Reproductive Medicine and the Society for Assisted Reproductive Technology. Mature oocyte cryopreservation: a guideline. Fertil Steril. 2013; 99:37-43. [PubMed: 23083924]

11. Dondorp W, de Wert G, Pennings G, Shenfield F, Devroey P, Tarlatzis B, et al. ESHRE Task Force on Ethics and Law. Oocyte cryopreservation for age-related fertility loss. Human Reproduction. 2012; 27:1231-1237. [PubMed: 22357771]

12. Lepkowski JM, Mosher WD, Davis KE, Groves RM, Van Hoewyk J. The 2006-2010 National Survey of Family Growth: sample design and analysis of a continuous survey. Vital Health Stat. 2010; series 2(150):1-35. (DHHS publication no. (PHS) 2010-1350).

13. Steiner AZ, Pritchard DA, Young SL, Herring AH. Peri-implantation intercourse lowers fecundability. Fertil Steril. 2014; 102:178-182. [PubMed: 24746744]

14. Nybo Andersen AM, Wohlfahrt J, Christens P, Olsen J, Melbye M. Maternal age and fetal loss: population based register linkage study. BMJ. 2000; 320:1708-1712. [PubMed: 10864550]

15. Centers for Disease Control and Prevention, American Society for Reproductive Medicine, Society for Assisted Reproductive Technology. Atlanta (GA): US Dept of Health and Human Services; 2013. 2011 Assisted Reproductive Technology National Summary Report.

16. Criteria for number of embryos to transfer: a committee opinion. Fertil Steril. 2013; 99:44-46. [PubMed: 23095140]

17. Vitek WS, Galárraga O, Klatsky PC, Robins JC, Carson SA, Blazar AS. Management of the first in vitro fertilization cycle for unexplained infertility: a cost-effectiveness analysis of split in vitro fertilization-intracytoplasmic sperm injection. Fertil Steril. 2013; 100:1381-1388. [PubMed: 23876534]

18. Little SE, Ratcliffe J, Caughey AB. Cost of transferring one through five embryos per in vitro fertilization cycle from various payor perspectives. Obstet Gynecol. 2006; 108:593-601. [PubMed: 16946220]

19. The costs of infertility treatments. McLean, VA: Resolve: the national infertility association. at www.resolve.org/family-building-options/making-treatment-affordable/the-costs-of-infertilitytreatment.html. [Accessed October 1, 2014] 
20. American Society for Reproductive Medicine. Birmingham, AL: Frequently asked questions about infertility. at www.asrm.org/awards/index.aspx?id=3012. [Accessed Oct 1, 2014]

21. Smit JG, Kasius JC, Eijkemans MJC, Koks CAM, van Golde R, Oosterhuis JGE, et al. The inSIGHT study: costs and effects of routine hysteroscopy prior to a first IVF treatment cycle. A randomised controlled trial. BMC Women's Health. 2012; 12:22. [PubMed: 22873367]

22. van Loendersloot, LL.; Moolenaar, LM.; Mol, BWJ.; Repping, S.; van der Veen, F.; Goddijn, M. Hum Reprod. Vol. 26. Oxford University Press; 2011 Nov. Expanding reproductive lifespan: a cost-effectiveness study on oocyte freezing; p. 3054-3060.

23. Hirshfeld-Cytron J, Grobman WA, Milad MP. Fertility preservation for social indications: a costbased decision analysis. Fertil Steril. 2012; 97:665-670. [PubMed: 22265038]

24. Cil AP, Bang H, Oktay K. Age-specific probability of live birth with oocyte cryopreservation: an individual patient data meta-analysis. Fertil Steril. 2013; 100:492-493. [PubMed: 23706339]

25. Copen CE, Daniels K, Vespa J, Mosher WD. First marriages in the United States: Data from the 2006-2010 national survey of family growth. Natl Health Stat Report. 2012 Mar 22.:1-21.

26. Kennedy S, Fitch CA. Measuring cohabitation and family structure in the United States: assessing the impact of new data from the Current Population Survey. Demography. 2012; 49:1479-1498. [PubMed: 22826006]

27. Ventura, SJ. NCHS data brief, no 18. Hyattsville, MD: National Center for Health Statistics; 2009. Changing patterns of nonmarital childbearing in the United States. (DHHS publication no. (PHS) 2009-1209).

28. Martinez, GM.; Daniels, K.; Chandra, A. National health statistics reports. Hyattsville, MD: National Center for Health Statistics; 2012. Fertility of men and women aged 15-44 years in the United States: National Survey of Family Growth, 2006-2010. (DHHS publication no. (PHS) 2012-1250). 


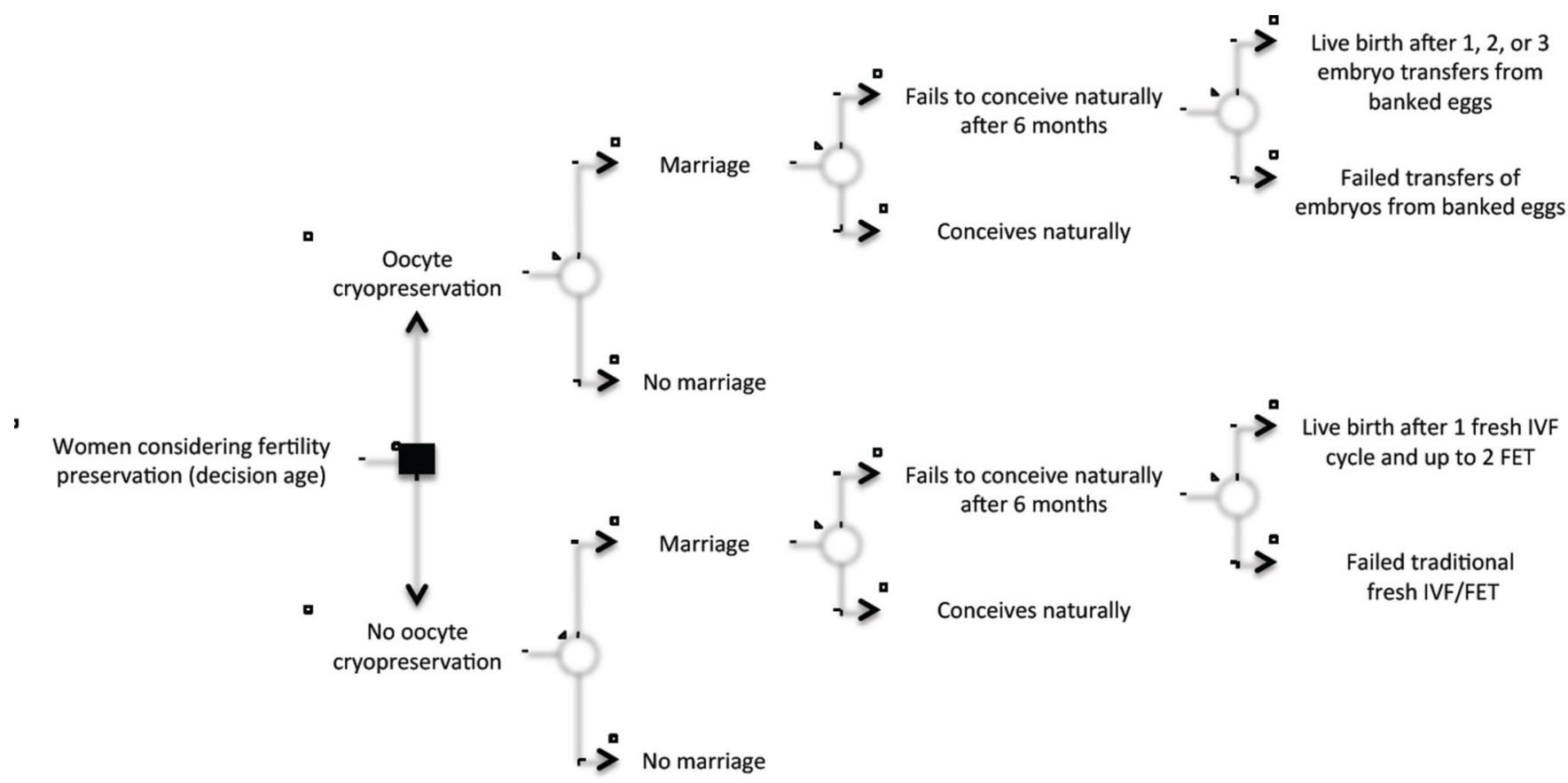

Figure 1. Simplified decision tree for Model A

For a simplified representation of the decision tree, chance nodes for probability of $2^{\text {nd }}$ and $3^{\text {rd }}$ cycles from frozen oocytes, $1^{\text {st }}$ and $2^{\text {nd }}$ FET, and miscarriage were not shown. Analysis was repeated for Decision Age between 25 and 40 years, assuming a 7-year time horizon before attempting pregnancy. In Model A (requires marriage to attempt conception), those who did not marry did not attempt pregnancy. In Model B, all women attempt pregnancy, either with a partner or with donor sperm.

Denotes decision node

ODenotes chance node 


\section{Probability of live birth after decision to cryopreserve oocytes}

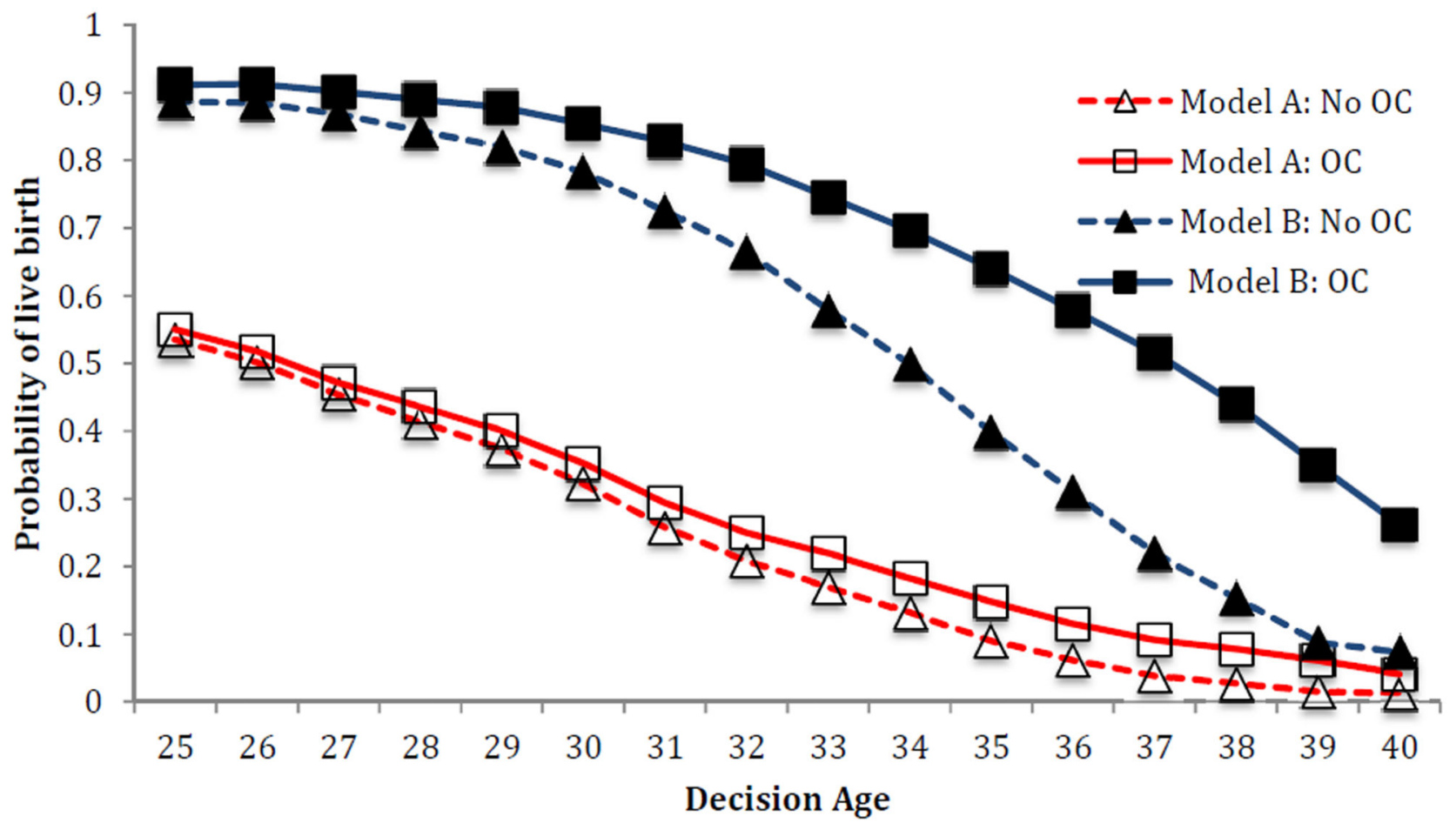

Figure 2.

The Y-axis represents the probability of live birth at Horizon Age, which is 7 years after Decision Age. Decision Age is presented on the X-axis. Solid line: cryopreserving oocytes (OC). Dashed line: no action. Model A represents women requiring marriage prior to attempting pregnancy. Model B represents women who do not require marriage prior to attempting pregnancy (will attempt pregnancy with husband, donor sperm, or unmarried male partner). 


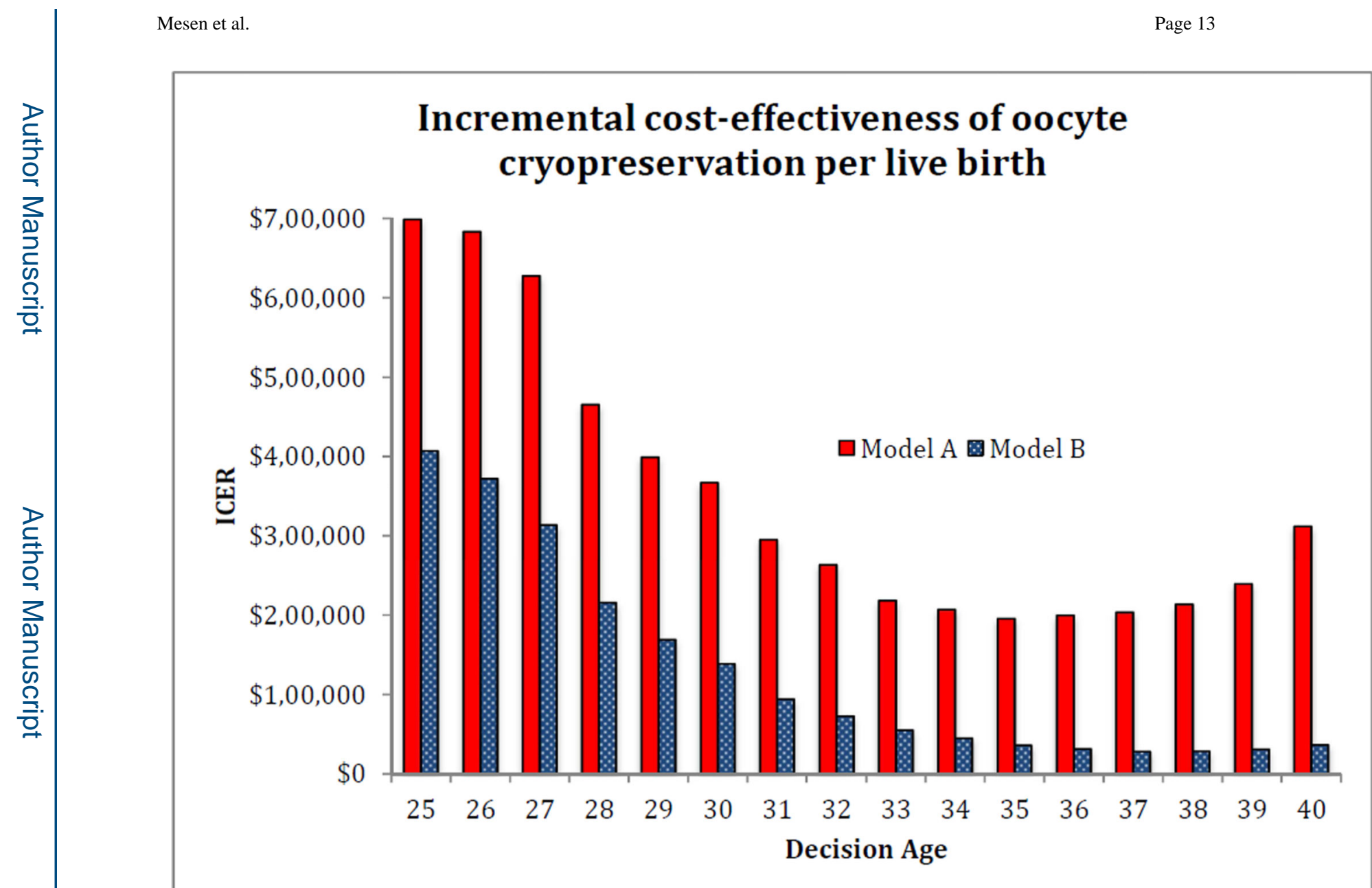

Figure 3.

Cost per additional live birth at Horizon Age when electing to cryopreserve oocytes versus no action at Decision Age, which is presented on the $\mathrm{X}$-axis. Model A represents women requiring marriage prior to attempting pregnancy. Model B represents women who do not require marriage prior to attempting pregnancy (will attempt pregnancy with husband, donor sperm or unmarried male partner). 


\section{Table 1}

Base-case cost and probability

\begin{tabular}{|lcccc|}
\hline Cost Estimates (USD) & Base Case & Low & High & Citation \\
Fervice & 13273 & 7183 & 28739 & $17-20$ \\
Fresh IVF cycle & 4169 & 3275 & 13107 & $17-20$ \\
Oocyte cryopreservation cycle & 9261 & 4631 & 13891 & Internal cost \\
Oocyte warming, ICSI, and embryo culture & 4416 & 2208 & 6624 & Internal cost \\
Oocyte storage & $300 /$ year & 100 & 1500 & 23 \\
\hline
\end{tabular}

Probability Estimates

Clinical situation

\section{Citation}

Marriage

12

Natural conception in 6 months

"Time to Conceive" study

Miscarriage rate

14

IVF-T live-birth rate

15

IVF-OC live birth rate

15

Supernumerary embryos for 1st and 2nd FET IntegraMed database

Supernumerary oocytes for 2nd and 3rd transfer

IntegraMed database

IVF-T - Traditional IVF in no OC group, IVF-OC - IVF in oocyte cryopreservation group, FET- Frozen embryo transfer 